\title{
Computational Analysis of Pyocyanin (Phz Gene) From Pseudomonas
}

\author{
Saranya Rathan ${ }^{1 *}$, Geethalakshmi Sundararaman ${ }^{2}$
}

${ }^{1}$ Department of Microbiology, Nehru Arts and Science College, 641105 Coimbatore

${ }^{2}$ Department of Biotechnology, Sree Narayana Guru College, 641105 Coimbatore

DOI: $10.36347 /$ sjams.2020.v08i09.028

| Received: 03.09.2020 | Accepted: 11.09.2020 | Published: 20.09.2020

*Corresponding author: Saranya Rathan

\section{Abstract}

\section{Original Research Article}

Pyocyanin is a biologically active phenazine produced by Pseudomonas aeruginosa. Pyocyanin is a blue redox-active secondary metabolite and a member of the large family of the tricyclic compounds. "Phenazines" Because of its solubility in chloroform it can be easily isolated. Pyocyanin or 1-hydroxy-5-methylphenazine is considered as a resonance hybrid of the mesomeric forms of $\mathrm{N}$-methyl-1-hydroxyphenazine is capable of undergoing a two-electron reduction to a colourless product, leukopyocyanin. It is believed to bestow $P$. aeruginosa with a competitive growth benefit in colonized tissue and is also thought to be a virulence factor in diseases such as cystic fibrosis and AIDS where patients are commonly infected by pathogenic Pseudomonads due to their immunocompromised state. Pyocyanin is also a chemically stimulating compound due to its unusual oxidation-reduction activity. Phenazine-1carboxylic acid, the predecessor to the bioactive phenazines, is produced from chorismic acid by enzymes determined in a seven-gene cistron in Pseudomonas aeruginosa. Phenzine-1-carboxylic acid is whispered to be converted to pyocyanin by the sequential actions of the putative. S-adenosylmethionine dependent $N$-methyltransferase $P h z \mathrm{M}$ and the putative flavin-dependent hydroxylase PhzS. Here we report the Predicted 3D Structure of PHZ S.

Keywords: Pyocyanin, Pseudomonas aeruginosa, leukopyocyanin.

Copyright @ 2020: This is an open-access article distributed under the terms of the Creative Commons Attribution license which permits unrestricted use, distribution, and reproduction in any medium for non-commercial use (NonCommercial, or CC-BY-NC) provided the original author and source are credited.

\section{INTRODUCTION}

Bacteria of the genus Pseudomonas are ubiquitous and are distinguished by their colourful secondary metabolite Phenazine. Phenazine derivatives have been known as redox reagents and the antibiotics which are produced by ample of microorganisms. One of phenazine derivatives, pyocyanin is a blue Phenazine pigment and is the produced by Pseudomonas aeruginosa. Pyocyanin (PCN) is synthesized through a series of complex steps mediated by gene products encoded by two phz ABCDEFG operons, and by the $p h z \mathrm{H}, p h z \mathrm{M}$ and $p h z \mathrm{~S}$ genes. The genes $p h z \mathrm{M}$ and $p h z \mathrm{~S}$ play essential roles in the pyocyanin biosynthesis. Pyocyanin has antimicrobial activity against bacteria, fungi, and protozoa. Due to the biotechnological application of pyocyanin inhibits the growth of crop pathogen and have also been suggested as food colorant pigments.

Phenazine derivatives have been known as the redox reagents and the antibiotics which are produced by several microorganisms. The production and characterization of these compounds were first carried out by Gessard [1]. One of phenazine derivatives, pyocyanin is a blue phenazine pigment and is produced by $P$. aeruginosa. Its chemical structure was elucidated by Wred and Strack [2] and Hillemann [3]. More than 6,000 Phenazine derivatives have been identified and described during the last two centuries. Pyocyanin down regulate the ciliary's beat frequency of respiratory epithelial cells by reducing cAMP and ATP, alter the calcium concentration by inhibition of plasma membrane $\mathrm{Ca}^{2+}$ - ATPase, and induce death in human neutrophils. Due to the abundance and biotechnological application of phenazines, pyocyanin have also been suggested as food colorant pigments. Pyocyanin is a nitric oxide (NO) antagonist in various pharmacological preparations, and has various pharmacological effects on eukaryotic and prokaryotic cells. Pyocyanin functions as an electron transfer agent on the membrane of several strains [4].

\section{Biosynthesis of pyocyanin (PCN) and phz gene}

Pyocyanin (PCN) is synthesized from chorismate through a series of complex steps mediated by gene products encoded by two phzABCDEFG operons, and by the $p h z \mathrm{H}, p h z \mathrm{M}$ and $p h z \mathrm{~S}$ genes. In the first step, catalyzed by the SAM-dependent methyltransferase phzM, PCA is converted to 5methylphenazine-1-carboxylic acid betaine. The second step, catalyzed by the NADH (or NADPH)-dependent 
flavoprotein monooxygenases. PhzS involves hydroxylative decarboxylation of 5-methylphenazine-1carboxylic acid betaine to pyocyanin. Pyocyanin only when cultures of $E$. coli expressing $p h z$ S were incubated with filtered extracts from cultures expressing $p h z \mathrm{M}$. When cultures expressing $p h z \mathrm{M}$ were incubated for $6 \mathrm{~h}$ with filtered extracts from cultures expressing $p h z \mathrm{~S}$, only PCA and 1-OHPHZ were detected and it is required for conversion of PCA to pyocyanin and PCN. There are two modifications for the conversion of PCA to pyocyanin: additions of the $\mathrm{N}$-methyl group, converting PCA to 5-methylphenazine-1-carboxylate betaine and hydroxylative decarboxylation of the betaine to form pyocyanin .There are two potential genes in the vicinity of phzA1B1C1DIE1F1G1 operon that could encode the required PCA- modifying enzymes.

\section{Antibiotic Action of Pyocyanin}

Biologically produced pyocyanin was purified by Stephen and his colleague 1981, and the nature of its antibacterial action was determined for several bacteria. The pigment was shown to be bactericidal for all susceptible organisms. Stephen and Hawkey, 2006 indicated that pyocyanin has antibiotic activity against other bacteria and fungi. It is bactericidal for many species including Escherichia coli, Staphylococcus aureus and Mycobacterium smegmatis. Pyocyanin is bactericidal for many species which can exist either in oxidized or reduced form, the latter being an unstable free radical which reacts rapidly with molecular oxygen. This activity may allow $P$. aeruginosa an advantage over competing bacteria occupying the same niche. Furthermore, pyocyanin has a variety of pharmacological effects on eukaryotic and prokaryotic cells [5]. [6, 7] indicated that pyocyanin has antimicrobial activity against bacteria, fungi, and protozoa, but it is little therapeutic value because it is quite toxic to eucaryotic cells, since pyocyanin inhibited mammalian cell respiration disrupt the beating of human cilia, and inhibit both epidermal cell growth and lymphocyte proliferation.

The presence of $p h z \mathrm{M}$ and $p h z \mathrm{~S}$ genes is necessary to produce pyocyanin. Regarding the relationship between the production rate of pyocyanin and increased pathogenicity of P.aeruginosa, hopefully gathering information about declining factors related to pyocyanin production, disabling this gene or its protein product will assist in curing patients infected with these bacteria. Jamileh et al. [8] demonstrated that combination of pyocyanin and colloidal silver nanoparticles demonstrated a strong antibacterial activity against the bacterial strains the increased antimicrobial effects of pyocyanin when mixed with colloidal silver nanoparticles, may enable its use as a hygienic, disinfectant material for hospitals and placemat risk for large numbers of microorganisms. However, an increase in the number of study samples would lead to more accurate results.

\section{Biocontrol}

Phenazines (PZs) are well-known pigmented, nitrogen-containing heterocyclic secondary metabolites produced by a variety of bacteria, like Pseudomonas [9]. The majority of the work on PZs has focused on the chemical or biological synthesis, redox properties, antitumor, or biological control activities. PZs have been recognized for their antibiotic properties for over 150 years [9]. PZs effectively control a wide range of plant pathogenic fungi and are a well-characterized mechanism of bacterial plant disease control [10-12]. Pseudomonas spp. produces three PZ derivatives PCA, 2-OH-PCA and a small amount of 2-OH-PZ [13]. The well-studied opportunistic pathogen of plants and animals, $P$. aeruginosa, produce the methylated PZ derivative pyocyanin (PYO) and a few $P$. aeruginosa strains also produce PCA [14].

Similarly, another well characterized biological control agent, $P$. fluorescens strain 2-79, produces only PCA [13]. The PZs produced by strain 30-84 are responsible for inhibition of Gaeumannomyces graminis tritici (Ggt), the take-all fungal pathogen of wheat. PCN was shown to control Fusarium oxysporum, the causative agent of tomato foot and root rot. Both PCA and PCN are involved in control of Pythium myriotylum, the causative agent of root rot of cocoyam [10]. PYO was shown to inhibit Septoriatritici of wheat. More importantly, they compete for colonization sites on the roots of agriculturally important crops, where they thrive as microcolonies (biofilms) and protect the plants from pathogenic fungi. The overall number of organisms competing with $P$. fluorescens for resources does not decline after this strain has colonized the root. This implies that it is not just the antibiotic activity of phenazines that is important for the ability of their producers to compete in the soil [15].

The importance of PZs in various physiological roles is only starting to be realized. An appropriate statement from a review by Laursen and Nielsen [16] states, "little is yet known about the physiological function of phenazines in their natural environment". Chemical fungicides and pesticides are comprehensively used in current farming practices to protect crops against diseases. However, recently their utilization has been concerned since chemical fungicides and pesticides are highly toxic. They can cause environmental contamination and/or the presence of fungicide/pesticides residues in food products and induce pathogen resistance [17]. Numerous synthetic chemicals may lose their effectiveness as a result of revised safety regulations, concern over no target effects or the development of resistance in pathogen and pest population. Biological control using microorganisms offers an alternative environmentally friendly strategy for controlling agricultural phytophatogens. Chitinases attract the attention as one of the potential candidates for control of phytopathogenic fungi and insect pests. The interest in 
chitin degrading enzymes chitinases with biofilm formation and bioactive organism and their application in control of pests and fungal pathogens have advanced significantly, because chitin is a major structural component of exoskeleton of arthropods, insects and fungal cell wall.

However, the production of chitinases enzyme in industries is to be one of the major economic variables, estimated to account for $12 \%$ of the total production cost and is presently uneconomic due to the high prices of the commercially available chitinase [18]. In recent years, there has been a lot of production of chitinase from microorganism. Recombinant DNA technology was much improved for the production of microbial chitinase. But the cost of production is high, so by using the chitin from the fish scale the denaturation of chitin was reduced and the production of chitinase was increased. A more efficient and economically viable process is essential to reduce the cost production of chitinases. The utilization of chitinase in various applications has received attention in biotechnology field. Therefore, investigate the optimization condition on expression of chitinase should be concerned in order to improve its productivity process, maximum its yield and reducing its production cost we used fish scale squander.

\section{Materials ANd Methods}

Extraction of genomic DNA $[\mathrm{CTAB} / \mathrm{NaCl}$ solution $(10 \%$ CTAB in $0.7 \mathrm{M} \mathrm{NaCl})]$

For extraction of genomic DNA, a standard protocol, CTAB/NaCl method [19] was followed. Extracted genomic DNA was individually stored at $4^{\circ} \mathrm{C}$ for further studies.

\section{Identification of $P$. putida by $16 \mathrm{~S}$ rRNA gene}

DNA sequencing enables us to perform a thorough analysis of DNA because it provides us with the most basic information of the sequence of all nucleotides. Genotypic identification of strains was done by $16 \mathrm{~S}$ rRNA sequence analysis. PCR amplification of 16S rRNA gene of Pseudomonas sp, was performed to determine the presence of Pseudomonas sp. in the template DNA by using the Lane, 1991 and Weisburg et al. [20] with universal forward and reverse primers. PCR primers were useful for the amplification of nearly full length small subunit rRNA genes.

Forward primer : 5'-AGAGTTTGATCATGGCTCAG-3', Reverse primer : 5'-TACGGCTACCTTGTTACGACTT-3'.

Following amplification, all the reaction tubes were stored at $4{ }^{\circ} \mathrm{C}$. A small aliquot of amplified product was run on agarose gel electrophoresis along with the DNA molecular marker $1.5 \mathrm{kbp}$ to analyze the product, according to Sambrook et al. [21].

\section{DNA sequencing}

The PCR product formed was further purified and sequenced and submitted to NCBI. The DNA sequencing was performed by using forward and reverses primers. A similarity search for the nucleotides sequence of lapD gene of the isolate was carried out using BLAST search at NCBI [22]. The 3D structure of the LapD protein was also predicted by using SWISS PRO database.

\section{PCR amplification of phzS gene [9]}

Amplification of phzS gene was done by using the following primers.

Forward primer : 5'-TCTGTCTGTTCCTGGTGGTT-3' Reverse primer : 5'-CGCAGGTCAATACTGTGAG-3'

A small aliquot of PCR product was run on agarose gel electrophoresis along with the DNA molecular weight marker to analyze the expected amplicon size of $1750 \mathrm{bp}$ units.

\section{DNA sequencing of $\mathrm{phzS}$ gene}

The DNA sequencing was performed by using forward and reverse primers. A similarity search for nucleotides sequence of $p h z \mathrm{~S}$ gene of the isolate was done by BLAST search at NCBI [22]. The 3D structure of the phzS protein was also predicted by using SWISS PROT database.

\section{PCR amplification of $p h z S$ gene}

In addition to the biofilm formation, many of the species of Pseudomonas are capable of producing bio-active compounds. Of various compounds, pyocyanin is an important one, with respect to the PGPR characteristics. Pyocyanin is a fluorescent green colour pigment which is having antimicrobial activity too [13]. Mavrodi et al. [9] reported that gene $p h z \mathrm{~S}$ for the production of pyocyanin. They also stated that the gene $p h z \mathrm{~S}$ is similar to bacterial monooxygenases. Then the 27 isolated $P$. putida is again subjected to the amplification of the pyocyanin gene of our interest. We amplified the gene $p h z \mathrm{~S}$ for the presence of an antibiotic compound pyocyanin.

Thomashow et al. [13] used phzS primers and produced 1215 bp of DNA encoding $p h \mathrm{zS}$ gene from $P$. aeruginosa and crystallized their enzymes responsible for the formation of the gene and relived the importance of the pyocyanin. The genes phzM and phzS play essential roles in the pyocyanin biosynthetic pathway. Transformation of the PCA-producing strain $P$. fluorescens 2-79 with $p h z \mathrm{M}$ and $p h z \mathrm{~S}$ triggered the biosynthesis of pyocyanin with large amounts [9].The pathway for biosynthesis of pyocyanin in $E$. coli by mixing induced cultures expressing phzMwith cultures expressing phzAlBlCIDIEIFIG1 or phzA2B2C2D2E2FE. coli expressing phzMand $p h z$ Sefficiently converted exogenously supplied PCA to pyocyanin. Some of the $P$. aeruginosa strains could not be able to produce pyocyanin, due to lack of $p h z$ Mand phzS genes. 


\section{RESULTS AND DiSCUSSION}

The following results were obtained from the computational analysis of the phzS gene.

1 atgagcgaac ccatcgatat cctcatcgce ggcgecggca tcggcggect cagttgcgcc 61 ctggcctgc accaggccgg catcggcaag gtcacgctge tggaaagcag cagcgagata 121 atcgacagcg gcgtcggcat caatatccag ccggcggcgg tcgaggccet catccatcga 181 ctgatgegec cggegetgge ggccaccgec atcccacce acgagctgeg ctacatcgac 241 cagagcggcg ccacggtatg gtccgagccg cgcggggtgg aagccggcaa cgcctatccg 301 cagtactcga tccatcgcgg cgaactgcag atgatcetgc tcgecgcggt gcgcgagcgc 361 ctcggccaac aggcggtacg caccggtctc ggcgtggagc gtatcgagga gcgcgacggc 421 cgcgtgctga tcggcgeccg cgacggacac ggcaagcccc aggcgetcgg tgccgatgtg 481 ctggtcggcg cegacggtat ccattcggeg gtccgcgegc acctgcatcc cgaccagagg 541 ccgetgtcce acggtgggat caccatgtgg cgcggcgtca ccgagttcga ccgcttcctc 601 gacggcaaga ccatgatcgt cgccaacgac gagcactggt cgcgectggt cgcctatccg 661 atctcggcgc gtcacgcggc cgaaggcaag tcgctggtga actgggtgtg catggtgccg 721 agcgecgecg tcggecagct cgacaacgag gecgactgga accgcgacgg gegcetggag 781 gcgatggccg cgttcttcge cgactgggac ctgggetggt tcgacatccg cgacctgctg 841 acccgcaacc agttgatcet gcagtacccg atggtagacc gegatccget gecgcactgg 901 ggccggggac gcatcaccet getcggcgac gccgcccacc tgatgtatcc gatgggcgec 961 aacggcgctt cgcaagcaat cetcgacggc atcgagctgg ccgccgcget ggcgcgcaac 1021 gccgacgtgg ccgcagcct gcgcgaatac gaagaagcgc ggcggccgac cgccaacaag 1081 atcatcctgg ccaaccgaga acgggaaaa gaggaatggg ccgcggcttc gcgaccgaag 1141 accgagaaga gcgcggcgct ggaagcgatc accggcagct accgcaacca ggtggaacgg 1201 accaccgagg aggtggtcga cetgctcggg cgcggcgget tcgcggtgga gcggatcgtc 1261 cggatcatcg gegatctgga cgaagccgec agcetgcggt tgctcggcaa ttgccgegag 1321 ccacgctag

Fig-1: Nucleotide Sequence of PHZ S gene

>PHZSMNNSNLAAARNLIQVVTGEWKSRCVYVATRLGLADLIESGIDSDETLAAAVGSDAERIHRLMRLLVAFE IFQGDTRDGYANTPTSHLLRDVEGSFRDMVLFYGEEFHAAWTPACEALLSGTPGFELAFGEDFYSYLKRCPDAG RRFLLAMKASNLAFHEIPRLLDFRGRSFVDVGGGSGELTKAILQAEPSARGVMLDREGSLGVARDNLSSLLAGE RVSLVGGDMLQEVPSNGDIYLLSRIIGDLDEAASLRLLGNCREAMAGDGRVVVIERTISASEPSPMSVLWDVHL FMACAGRHRTTEEVVDLLGRGGFAVERIVDLPMETRMIVAARA

Fig-2: Protein Sequence of PHZ S gene

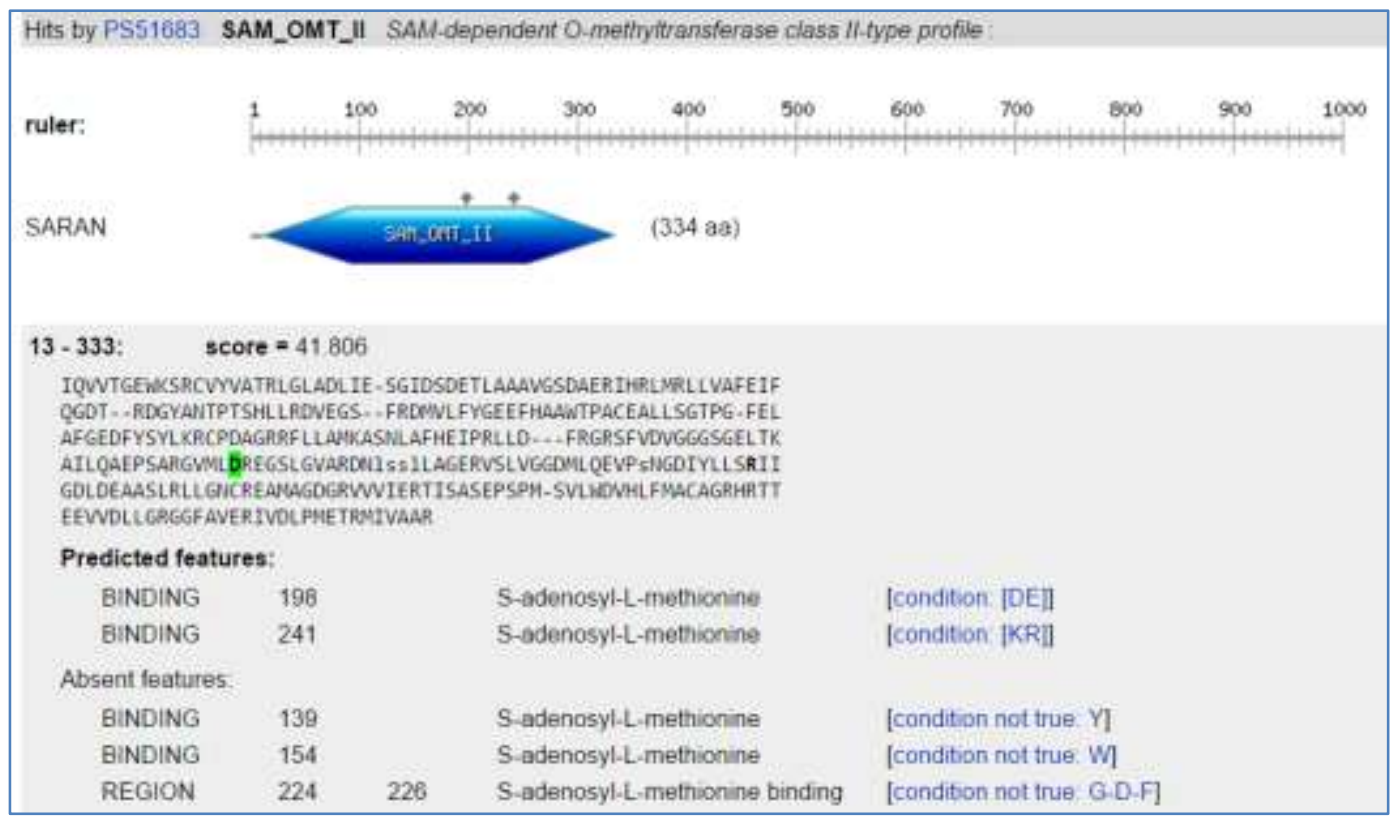

Fig-3: ScanPROSITE prediction of PHZ S 


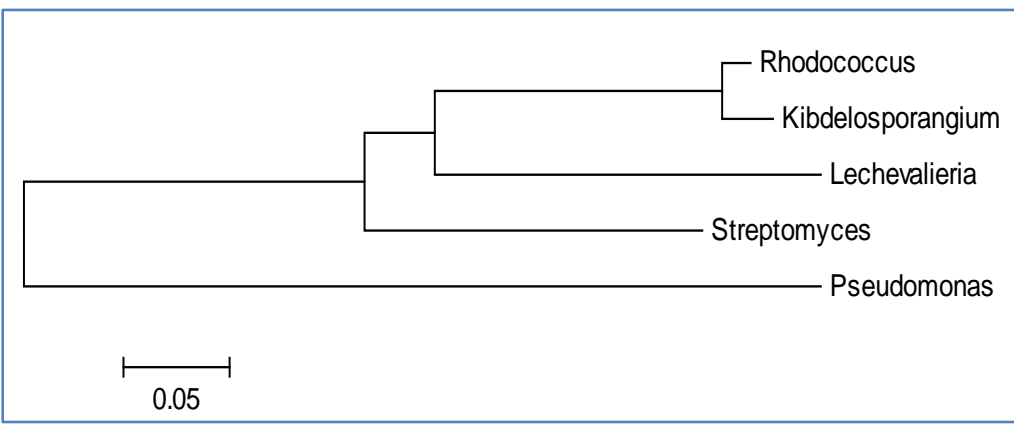

Fig-4: MSA of PHZ S

Fasuderonsm on

Lechersilieria seroeolonsgenea

streptorysens $m$.

nibdalorporasgiten aridien

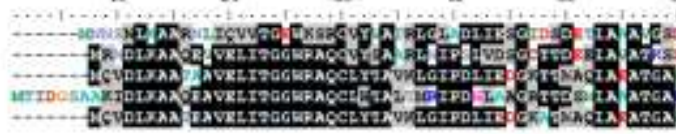

Vapudomonsen ap

Lachermilista serocolomigenes

whodococes: rhodn:

stroptaryces ap

sp

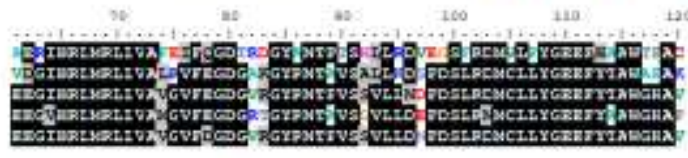

Vatudomotak mp

Lecheralieris narocolonigenea

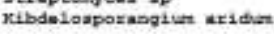

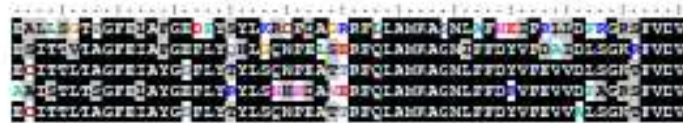

zavudomotas ap

Lecheralieris aerocolonigenea

nhodococecul thedni

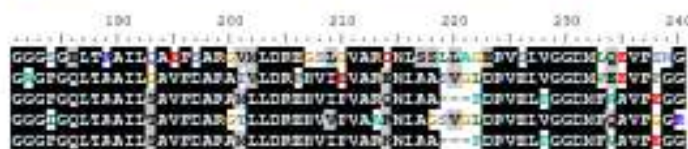

raeudenosks $2 x$

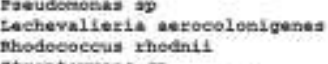

streptaryced so
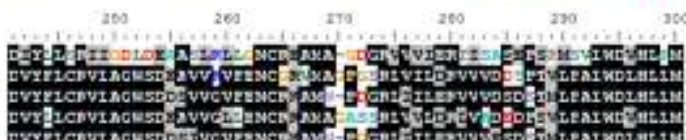

Patudenotas SD

Lecheralleria aerocolomsgenes

Mhodesocens thedini

ribdelosporabilum aridum

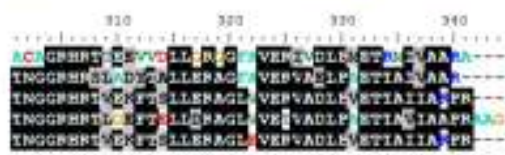

Fig-5: Phylogenetic tree for PHZ S

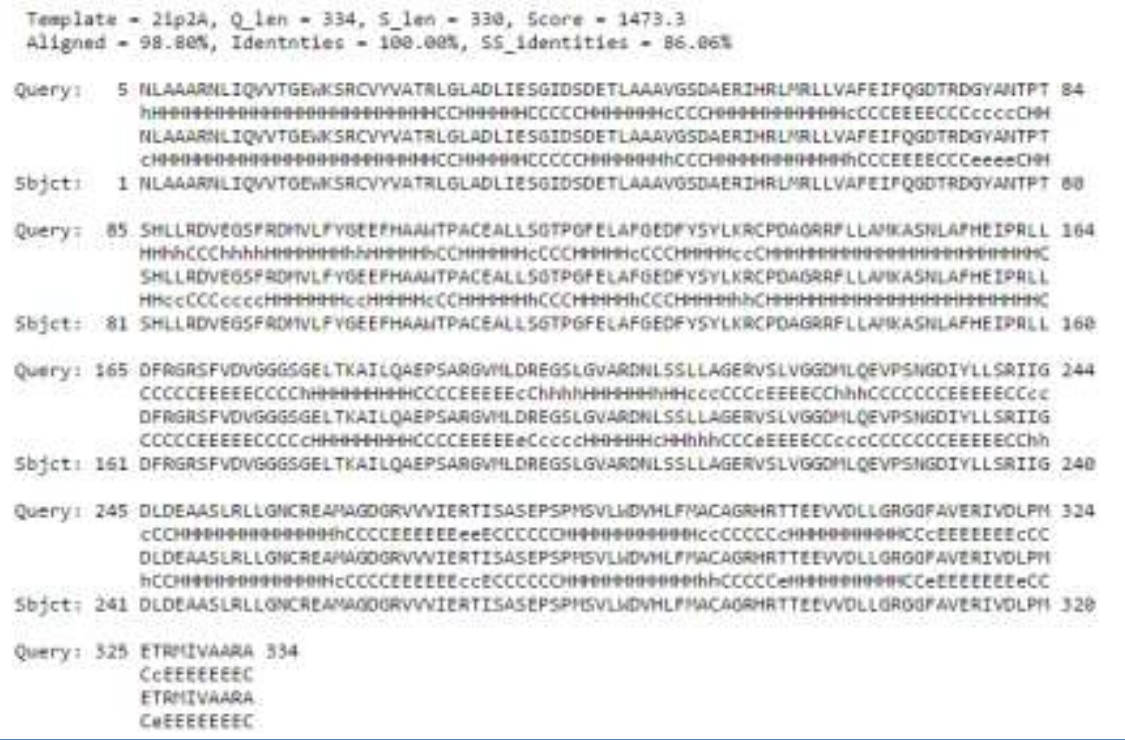

Fig-6: Secondary Structure details of PHZ S 


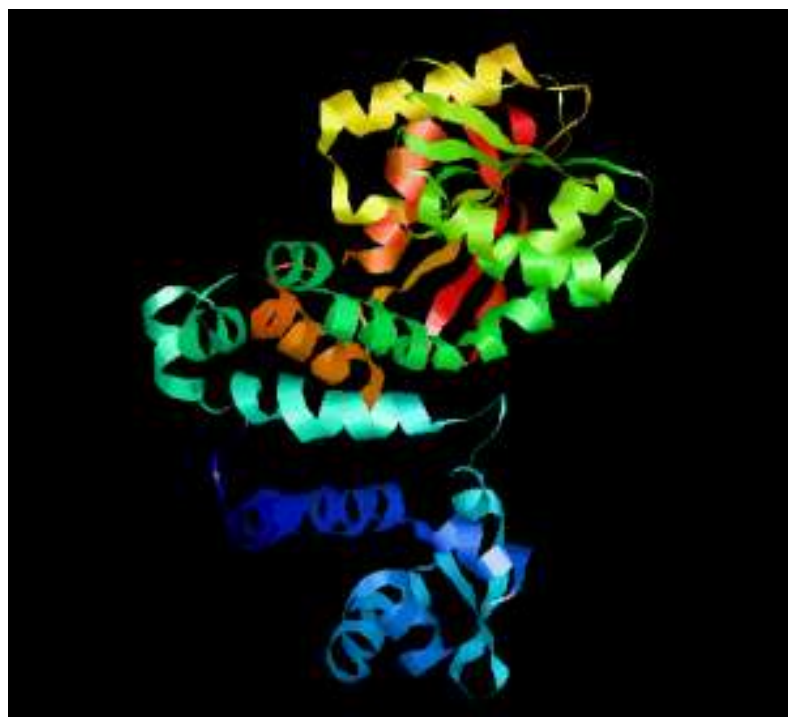

Fig-7: Predicted 3D Structure of PHZ S

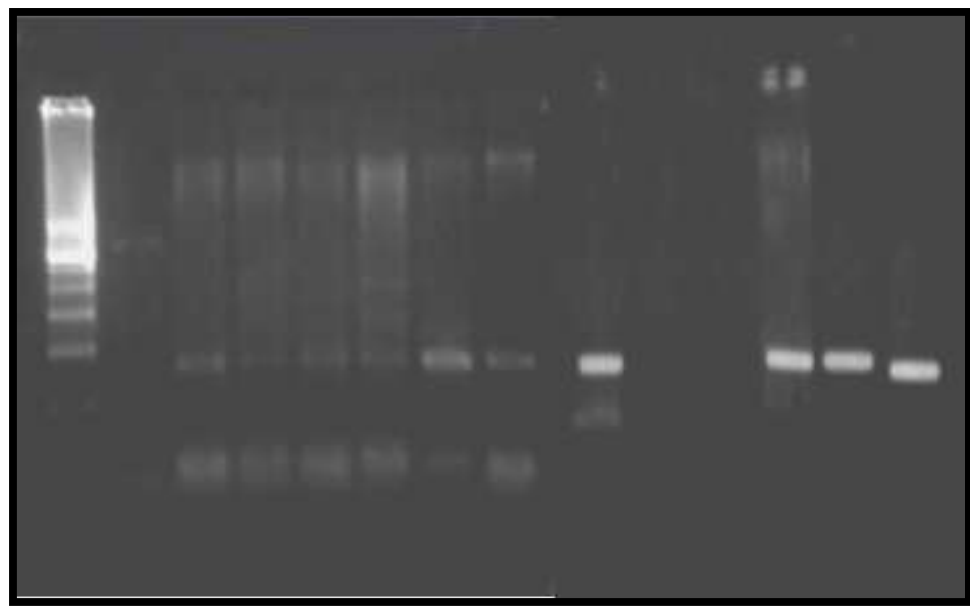

Fig-8: PCR amplification of $p h z S$ gene

Figure shows the 10 strain gives the positive result of $1215 \mathrm{bp}$ units. Give more explanation on results.

Thomashow et al. [13] reported the significant role of $p h z \mathrm{~S}$ gene to produce pyocyanin, by comparing with pyocyanin deficient phenotype by inactivating phzM gene. In the present study, of 27 isolates tested, 10 of them were positive for pyocyanin. Being an essential bio-component, bacteria with the ability of producing pyocyanin also could be used as biocontrol agent. Pyocyanin has been reported to have bactericidal effect on various plant pathogens, including Rhizoctoniasolani [13], P. chlororaphis [23]. Pyocyanin producing $P$. aeruginosa environmental isolates have been recognized as putative biological control agents against phytopathogenic fungi and bacteria in agriculture fields [24].

\section{CONCLUSiON}

In conclusion, $P$. putida with dual characters, viz. biofilm formation and pyocyanin production could be effectively used as plant protection and disease management systems in various agricultural practices. Since all the isolates have been confirmed as nonpathogenic in nature, an effective integrated plant and pest management system could be developed, which is a most-wanted, significant concept required present days. These kinds of formulations are not only supporting the plant growth, but they could biodegrade pesticide residues in soil and nurturing the agricultural soil by providing the needs of soil.

\section{REFERENCES}

1. Gessard C. Nouvelles recherches sur le microbe pyocyanique. Ann. Inst. Pasteur. 1890;4:88.

2. Strack E, Friedel W, Hambsch K. Hoppe-Seyler's 2. physiol.

3. Hillemann H. Position of the methyl groups in pyocyanine and attempts to synthesize isopyocyanine. Ber Dtsch Chem Ges B. 1938;71:46-52.

4. Friedheim EA. Pyocyanine, an accessory respiratory enzyme. The Journal of experimental medicine. 1931 Jul 31;54(2):207. 
5. Saha MR, Jahangir R, Vhuiyan MM, Biva IJ. In vitro nitric oxide scavenging activity of ethanol leaf extracts of four Bangladeshi medicinal plants. Stamford Journal of Pharmaceutical Sciences. 2008;1(1):57-62.

6. Lau GW, Hassett DJ, Ran H, Kong F. The role of pyocyanin in Pseudomonas aeruginosa infection. Trends in molecular medicine. 2004 Dec 1;10(12):599-606.

7. Baron SS, Rowe JJ. Antibiotic action of pyocyanin. Antimicrobial agents and chemotherapy. $1981 \mathrm{Dec}$ 1;20(6):814-20.

8. Portha B, Chavey A, Movassat J. Early-life origins of type 2 diabetes: fetal programming of the betacell mass. Experimental diabetes research. 2011 Oct 24;2011.

9. Mavrodi DV, Bonsall RF, Delaney SM, Soule MJ, Phillips G, Thomashow LS. Functional analysis of genes for biosynthesis of pyocyanin and phenazine1-carboxamide from Pseudomonas aeruginosa PAO1. Journal of bacteriology. 2001 Nov 1;183(21):6454-65.

10. Anjaiah V, Koedam N, Nowak-Thompson B, Loper JE, Höfte M, Tambong JT, Cornelis P. Involvement of phenazines and anthranilate in the antagonism of Pseudomonas aeruginosa PNA1 and Tn 5 derivatives toward Fusarium spp. and Pythium spp. Molecular Plant-Microbe Interactions. 1998 Sep;11(9):847-54.

11. Walsh JJ, Penta B, Dieterle DA, Bissett WP. Predictive ecological modeling of harmful algal blooms. Human and Ecological Risk Assessment: An International Journal. 2001 Sep 1;7(5):1369-83.

12. Raaijmakers JM, Vlami M, De Souza JT. Antibiotic production by bacterial biocontrol agents. Antonie van leeuwenhoek. 2002 Dec 1;81(1-4):537.

13. Mazzola M, Cook RJ, Thomashow LS, Weller DM, Pierson LS. Contribution of phenazine antibiotic biosynthesis to the ecological competence of fluorescent pseudomonads in soil habitats. Applied and environmental microbiology. 1992 Aug 1;58(8):2616-24.
14. Mahajan-Miklos S, Tan MW, Rahme LG, Ausubel FM. Molecular mechanisms of bacterial virulence elucidated using a Pseudomonas aeruginosaCaenorhabditis elegans pathogenesis model. Cell. 1999 Jan 8;96(1):47-56.

15. Dietrich LE, Price-Whelan A, Petersen A, Whiteley $\mathrm{M}$, Newman DK. The phenazine pyocyanin is a terminal signalling factor in the quorum sensing network of Pseudomonas aeruginosa. Molecular microbiology. 2006 Sep;61(5):1308-21.

16. Laursen JB, Nielsen J. Phenazine natural products: biosynthesis, synthetic analogues, and biological activity. Chemical reviews. 2004 Mar 10;104(3):1663-86.

17. Chang CT, Esterman A. Diagnostic delay among pulmonary tuberculosis patients in Sarawak, Malaysia: a cross-sectional study. Rural \& Remote Health. 2007 Apr 1;7(2).

18. Suresh G. Impact-RSV study group report. Pediatrics. 1999 Oct 1;104(4):993-4.

19. Jaufeerally-Fakim Y, Autrey JC, Daniels MJ, Dookun A. Genetic polymorphism in Xanthomonas albilineans strains originating from 11 geographical locations, revealed by two DNA probes. Letters in applied microbiology. 2000 Apr;30(4):287-93.

20. Weisburg WG, Barns SM, Pelletier DA, Lane DJ. $16 \mathrm{~S}$ ribosomal DNA amplification for phylogenetic study. Journal of bacteriology. 1991 Jan 1;173(2):697-703.

21. Sambrook J, Fritsch EF, Maniatis T. Molecular cloning: a laboratory manual. Cold spring harbor laboratory press; 1989.

22. Altschul SF, Lipman DJ. Protein database searches for multiple alignments. Proceedings of the National Academy of Sciences. 1990 Jul 1;87(14):5509-13.

23. Bloemberg GV, Lugtenberg BJ. Molecular basis of plant growth promotion and biocontrol by rhizobacteria. Current opinion in plant biology. 2001 Aug 1;4(4):343-50.

24. Rangarajan A, Weinberg RA. Comparative biology of mouse versus human cells: modelling human cancer in mice. Nature Reviews Cancer. 2003 Dec;3(12):952-9. 